\title{
The immunostimulatory effects of retinoblastoma cell supernatant on dendritic cells
}

\author{
Juan Ma ${ }^{1 凶}$, Huamin $\mathrm{Han}^{1,2}$, Li Ma ${ }^{3}$, Changzhen Liu ${ }^{1}$, Xin Xue ${ }^{4}$, Pan Ma ${ }^{1}$, Xiaomei Li ${ }^{1}$, Hua Tao ${ }^{1}$ \\ ${ }^{1}$ CAS Key Laboratory of Pathogenic Microbiology and Immunology, Institute of Microbiology, Chinese Academy of Sciences, \\ Beijing 100101, China \\ ${ }^{2}$ Key Laboratory of Infection and Immunity, Institute of Biophysics, Chinese Academy of Sciences, Beijing 100101, China \\ ${ }^{3}$ Department of Obstetrics and Gynecology, China-Japan Friendship Hospital, Beijing 100029, China \\ ${ }^{4}$ Department of Immunology, Basic Medical Theory of Chinese Medicine, China Academy of Chinese Medical Sciences, \\ Beijing 100700, China \\ $\bowtie$ Correspondence: majuan96@sina.com (J. Ma)
}

Received December 22, 2013 Accepted January 20, 2014

\begin{abstract}
Dendritic cells (DCs) are crucial for the induction and maintenance of tumor-specific immune responses. Studies have shown that tumor-associated DCs are immunosuppressed in some human tumors. However, phenotype and function of DCs in retinoblastoma (RB) remain unclear. $R B$ cell supernatant (RBcs) was used to treat DCs in vitro to explore the effect of RB cells on DCs. DCs were generated from peripheral blood mononuclear cells of healthy donors. On day 5 of culture, DCs were treated with RBcs for $\mathbf{2 4} \mathrm{h}$, and then purified using magnetic beads. The maturation of DCs was induced by TNF- $\alpha$ or LPS. After treatment with RBcs, expression of co-stimulatory molecules CD80 and CD86 was elevated in DCs, accompanied by increased production of IL12p70, TNF- $\alpha$, IL-6, IL-1 $\beta$, and IL-8 but decreased production of IL-10. RBcs neither inhibited DC maturation nor promoted DC apoptosis. Moreover, RBcs-exposed DCs stimulated allogenetic $T$ cell proliferation and $T$ cellderived cytokine production. These results indicate that RBcs can improve DCs' antigen presenting function and capability to activate $T$ cells, suggesting that RB cells may have an immunostimulatory effect on DCs, and DCbased immunotherapy may be adopted in the treatment of RB.
\end{abstract}

Juan Ma and Huamin Han contributed equally to this work.
KEYWORDS retinoblastoma, dendritic cell, anti-tumor immunity, immunotherapy

\section{INTRODUCTION}

Retinoblastoma (RB) is the most common primary intraocular malignant tumor in childhood, and the morbidity of RB is about 11 per million children below age 5 worldwide (Houston et al., 2011). The prognosis of RB patients has been dramatically improved by systematic enucleation (Khetan et al., 2013), external cryotherapy, local thermotherapy (Schueler et al., 2003), and brachytherapy (Merchant et al., 2004). Although these methods are successful at controlling the growth of the primary tumor, they cannot prevent the development of metastasis, which remains universally fatal. Moreover, there are some severe side effects related to radiotherapy or chemotherapy. Cancer immunotherapies have been generally in steady progress in this field over the past decade, particularly in the treatment of metastatic skin melanoma.

Dendritic cells (DCs) are crucial for the induction and maintenance of antitumor immune responses. Tumor-specific antigens bound to molecules of the major histocompatibility complex $(\mathrm{MHC})$ on the surface of DCs are processed, then presented to and recognized by T cells. In addition, DCs provide some critical molecules, such as costimulatory signals and cytokines, to the T cells for their full activation. Actually, tumor-infiltrating DCs (TIDCs) are associated with prolonged survival and reduced incidence in some metastatic human tumors (Dieu-Nosjean et al., 2008; 
A
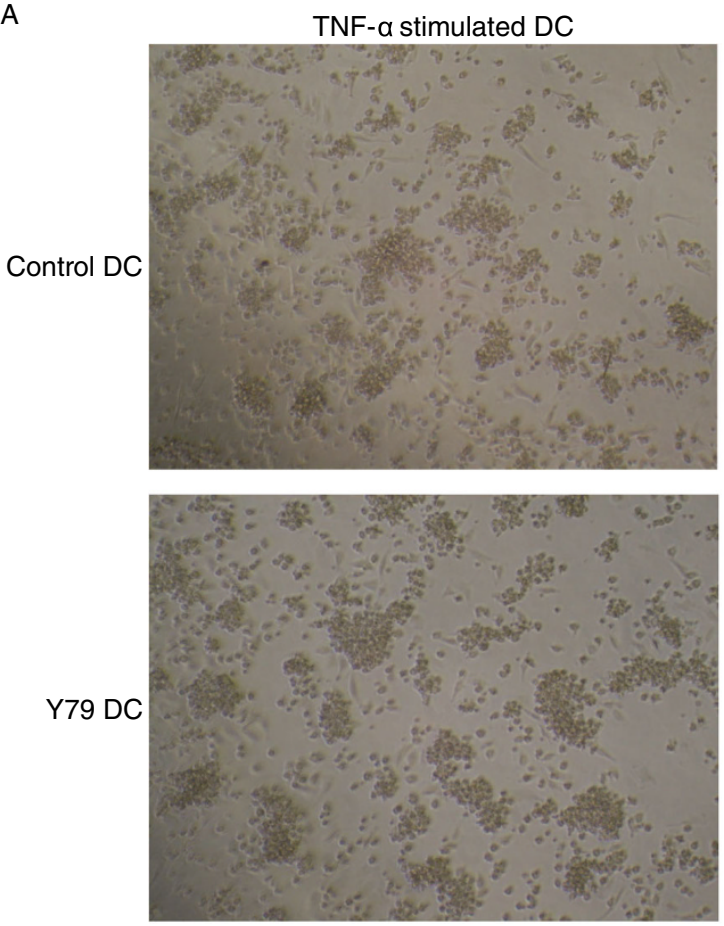

B
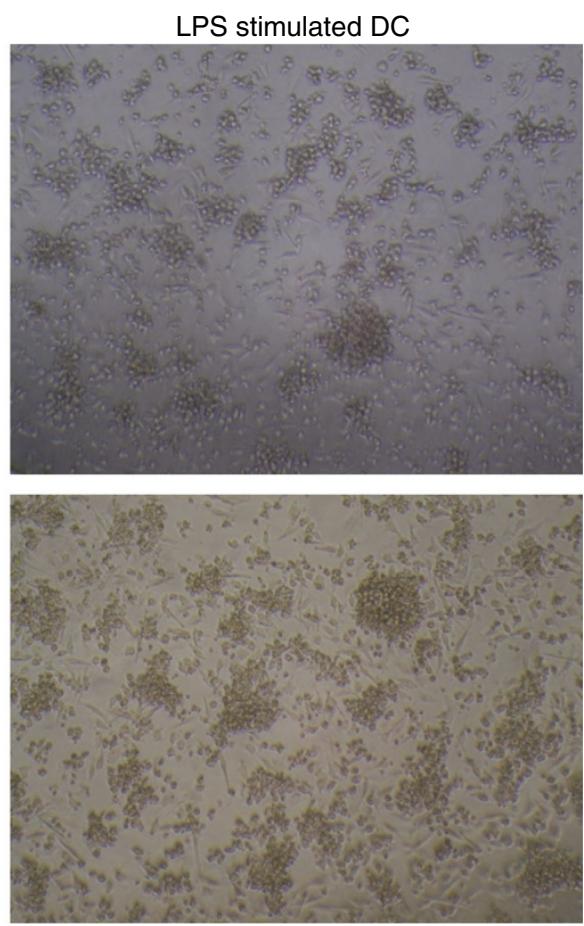

Figure 1. The photomicrograph of DC cultures (200x). Control DCs or RBcs-exposed DCs were treated with $20 \mathrm{ng} / \mathrm{mL} \mathrm{TNF}-\alpha$ (A) or $1 \mu \mathrm{g} / \mathrm{mL}$ LPS (B) for $24 \mathrm{~h}$. Y79 DC: RBcs-exposed DCs.

Iwamoto et al., 2003; Ladanyi et al., 2007; Nakakubo et al., 2003). However, in some other conditions, TIDCs are functionally compromised. TIDCs are phenotypically and functionally defective in colorectal cancer (Chaux et al., 1997) and melanoma (Ataera et al., 2011; Stoitzner et al., 2008), and a positive correlation of TIDCs with the poor prognosis was found in colorectal cancer (Sandel et al., 2005) and breast cancer (Treilleux et al., 2004). In hepatocellular carcinoma, circulating DCs also exhibit an immature phenotype (Beckebaum et al., 2004).

Until now, the effect of RB on human DCs has not been explored. In the present study, we used RB cell supernatant (RBcs) to mimic the tumor milieu, and performed a detailed study on the phenotype of DCs treated with RBcs. Subsequently, we investigated the effect of RBcs-exposed DCs on allogenetic $T$ cell proliferation and cytokine production. Our study demonstrates that RBcs improves DCs' antigen presenting function and capability to activate T cells, and DCbased immunotherapy may be adopted in the treatment of RB.

\section{RESULTS}

\section{Induction of co-stimulatory molecules CD80 and CD86} in $\mathrm{DCs}$ by RBcs

Five-day old DCs were treated with or without RBcs for $24 \mathrm{~h}$. On day 6 , maturation of DCs was induced by adding $20 \mathrm{ng} /$ $\mathrm{mL}$ TNF- $\alpha$ or $1 \mu \mathrm{g} / \mathrm{mL}$ LPS. After $24 \mathrm{~h}$, all DCs appeared as big loosely adherent clumps or isolated floating cells with the typical dendritic morphology (Fig. 1). The expression of DC markers (CD1a and CD83), MHC class molecules (HLA-ABC and HLA-DR) and co-stimulatory molecules (CD40, CD80, and CD86) was determined by flow cytometry (Fig. 2). Compared with control DCs, RBcs-exposed DCs expressed higher levels of CD80 and CD86, but similar levels of CD1a, CD83, HLA-ABC, HLA-DR, and CD40. These data suggest that RB cells may enhance DCs' capacity in priming $T$ cell responses, whereas have no effect on the maturation of DCs.

Induction of IL-12p70, TNF- $\alpha$, IL-6, IL-1 $\beta$, IL-8 and inhibition of IL-10 in DCs by RBcs

In addition to co-stimulatory molecules, DC-derived cytokines also play an important role in priming T cell response. Cytokine production in DCs was assayed using CBA Human Inflammation Kit. Compared with control DCs, RBcsexposed DCs secreted more IL-12p70, TNF- $\alpha$, IL-6, IL-1 $\beta$, and IL-8, but less IL-10, a potent immunosuppressive cytokine (Fig. 3). Moreover, alterations in cytokine production induced by RBcs in LPS-matured DCs were more significant than those in TNF- $\alpha$-matured DCs (Fig. 3B). These results further indicate that RB cells can increase DCs' capacity to activate $T$ cells.

\section{No effect of RBcs on DC apoptosis}

As tumor cells can escape immune destruction by inducing DC apoptosis (Kanto et al., 2001; Kiertscher et al., 2000; Ma 
A

TNF- $\alpha$ stimulated DC

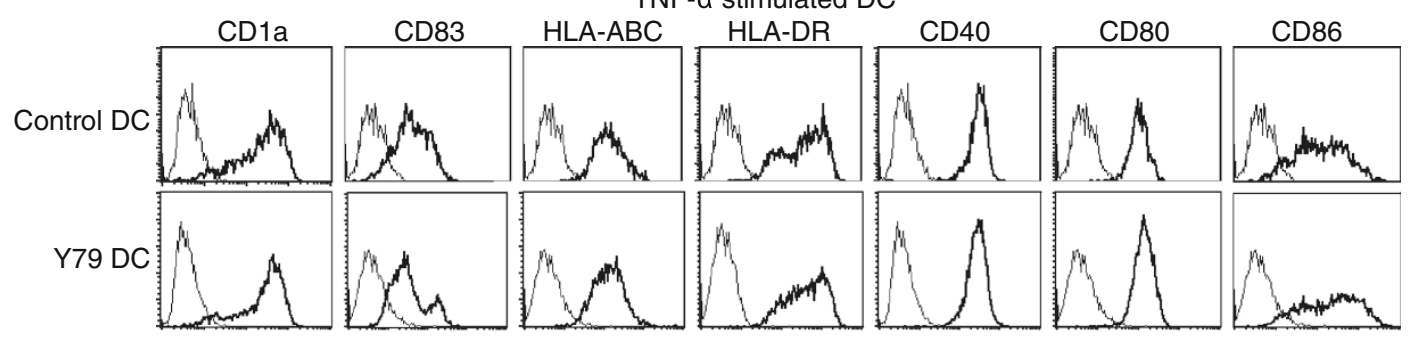

B

LPS stimulated DC
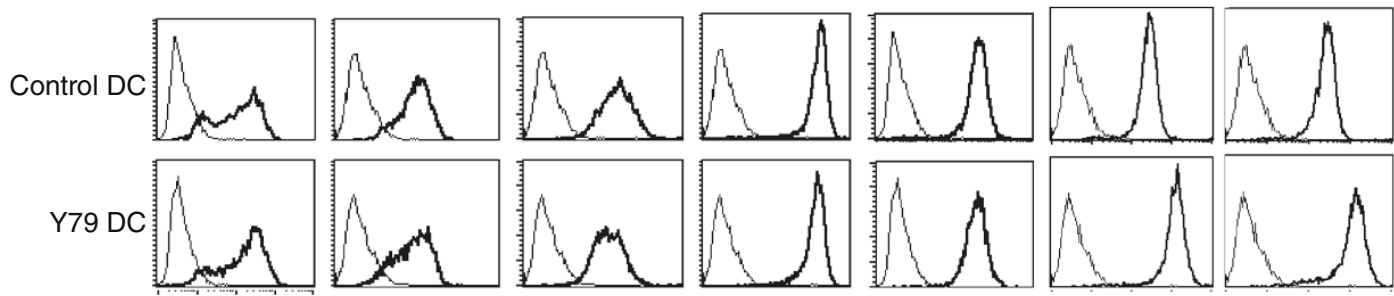

Figure 2. Expression of DC markers, MHC and co-stimulatory molecules in RBcs-exposed DC. Control DCs or RBcs-exposed DCs were treated with $20 \mathrm{ng} / \mathrm{mL}$ TNF- $\alpha$ (A) or $1 \mu \mathrm{g} / \mathrm{mL}$ LPS (B) for $24 \mathrm{~h}$. The cells were then harvested for immunofluorescence staining and flow cytometry. Bold lines denote fluorescence when stained with fluorochrome-conjugated antibody to the indicated antigen, and fine lines denote fluorescence when stained with isotype control mAb. Data shown are a representative experiment of five. Y79 DC: RBcs-exposed DCs.

et al., 2010), we evaluated whether RB cells could affect DC apoptosis (Fig. 4). FITC-Annexin-V and propidium iodide (PI) were used to stain DCs, and the proportion of apoptotic cells (Annexin ${ }^{+} / \mathrm{PI}^{-}$) was determined by flow cytometry. No significant difference in apoptotic proportion was observed between control DCs and RBcs-exposed DCs. DC apoptosis was further assessed by a FACS-based TUNEL assay utilizing FITC-dUTP. It was found that the apoptotic rate of RBcs-exposed DCs was similar to that of control DCs. These data indicate that RB cells have no effect on DC apoptosis.

\section{Stimulation of T cell proliferation by RBcs-exposed DCs}

To verify the immunostimulatory effect of RBcs-exposed DCs, DCs treated with or without RBcs were irradiated and then used to stimulate purified allogeneic T cells $\left(2 \times 10^{5}\right.$ per well). Proliferation of T cells was analyzed by measuring the incorporation of $\left[{ }^{3} \mathrm{H}\right]$-thymidine. As shown in Fig. 5, a significant increase in $\mathrm{T}$ cell proliferation was observed when they were co-cultured with $\mathrm{RBcs}$-exposed $\mathrm{DCs}$ at T/DC ratio of 500:1 and 100:1, indicating that DCs' capacity to activate $\mathrm{T}$ cells was enhanced after treatment with RBcs.

\section{Induction of T cell-derived cytokines by RBcs-exposed DCs}

To further confirm the immunostimulatory effect of RBcsexposed DCs, levels of T cell-derived cytokines were measured in above T-DC co-culture system using the CBA human Th1/Th2/Th17 cytokine kit. It was observed that
RBcs-exposed DCs stimulated T cells to secrete much more cytokines than control DCs at different T/DC ratio, including IFN- $y$, IL-2, TNF- $\alpha$, IL-6, IL-10, and IL-17 (Fig. 6). On the contrary, no IL-4 production was found in T cells treated with either control DCs or RBcs-exposed DCs. These data indicate that RBcs-exposed DCs induce T cells to produce Th1 and Th17 cytokines predominantly.

\section{DISCUSSION}

DCs play a critical role in tumor immune surveillance by initiating tumor-specific immune responses. Clinically, infiltration of DCs is correlated with a better prognosis in various human tumors (Dieu-Nosjean et al., 2008; Iwamoto et al., 2003; Ladanyi et al., 2007; Nakakubo et al., 2003), which is attributed to inhibition of tumor growth and metastasis by DCs (Lim et al., 2007; Movassagh et al., 2004; PreynatSeauve et al., 2007). However, the immune function of DCs is sometimes suppressed due to some factors produced by tumors, such as IL-10, transforming growth factor- $\beta$ (TGF- $\beta$ ), vascular endothelial growth factor (VEGF), IL-6, macrophage colony-stimulating factor (M-CSF), and prostaglandin $E_{2}\left(P_{2}\right)$ (Preynat-Seauve et al., 2006; Zou, 2005). The molecular mechanisms of DC dysfunction may be related to activation of the signal transducers and activators of transcription 3 (STAT3) and inhibition of nuclear factor kappa-B (NF-kB) (Gottfried et al., 2008; Wang et al., 2004).

Until now, the role of DCs in RB has not been explored, and the effect of RB on DCs remains unknown. In the 
A
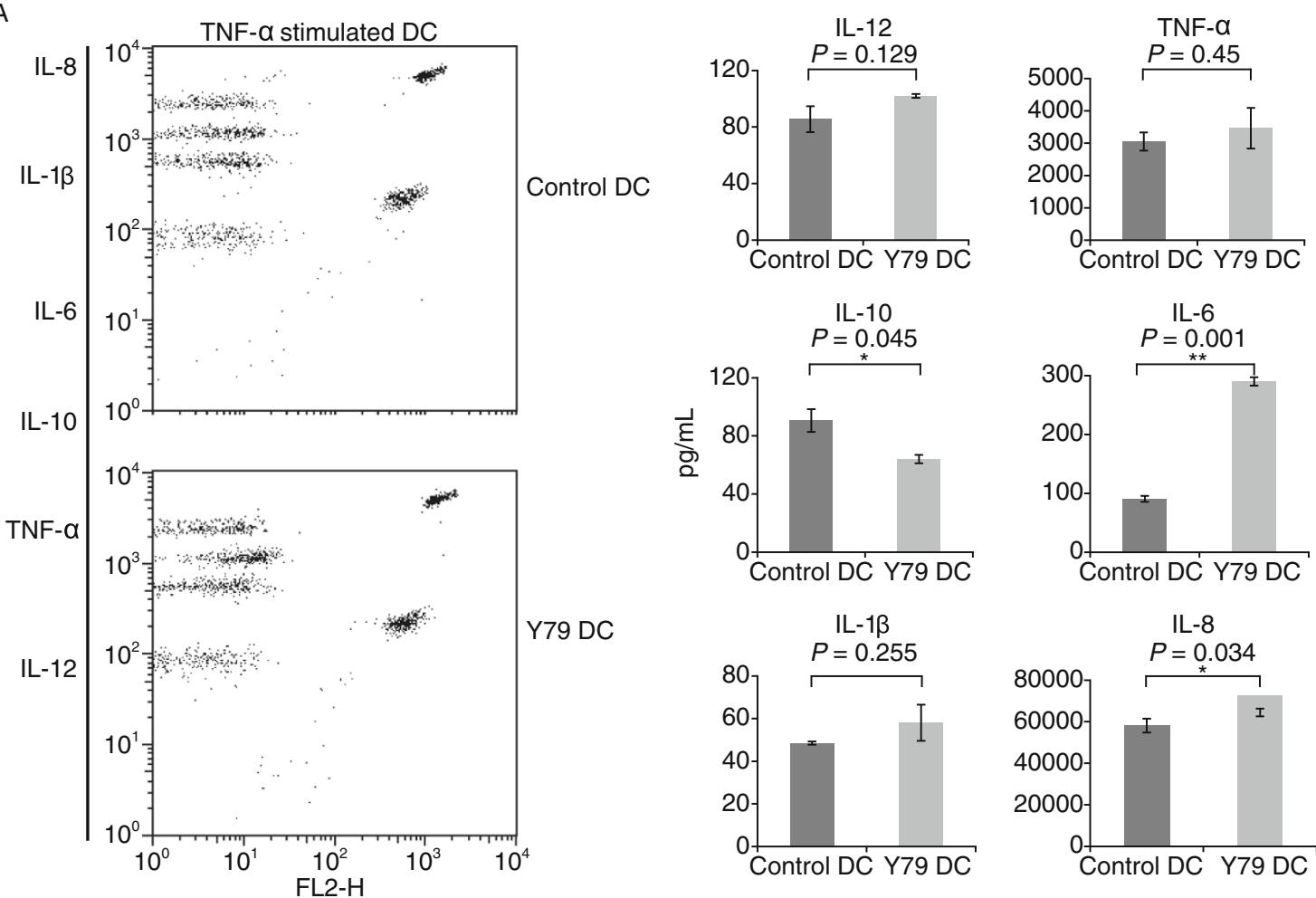

B
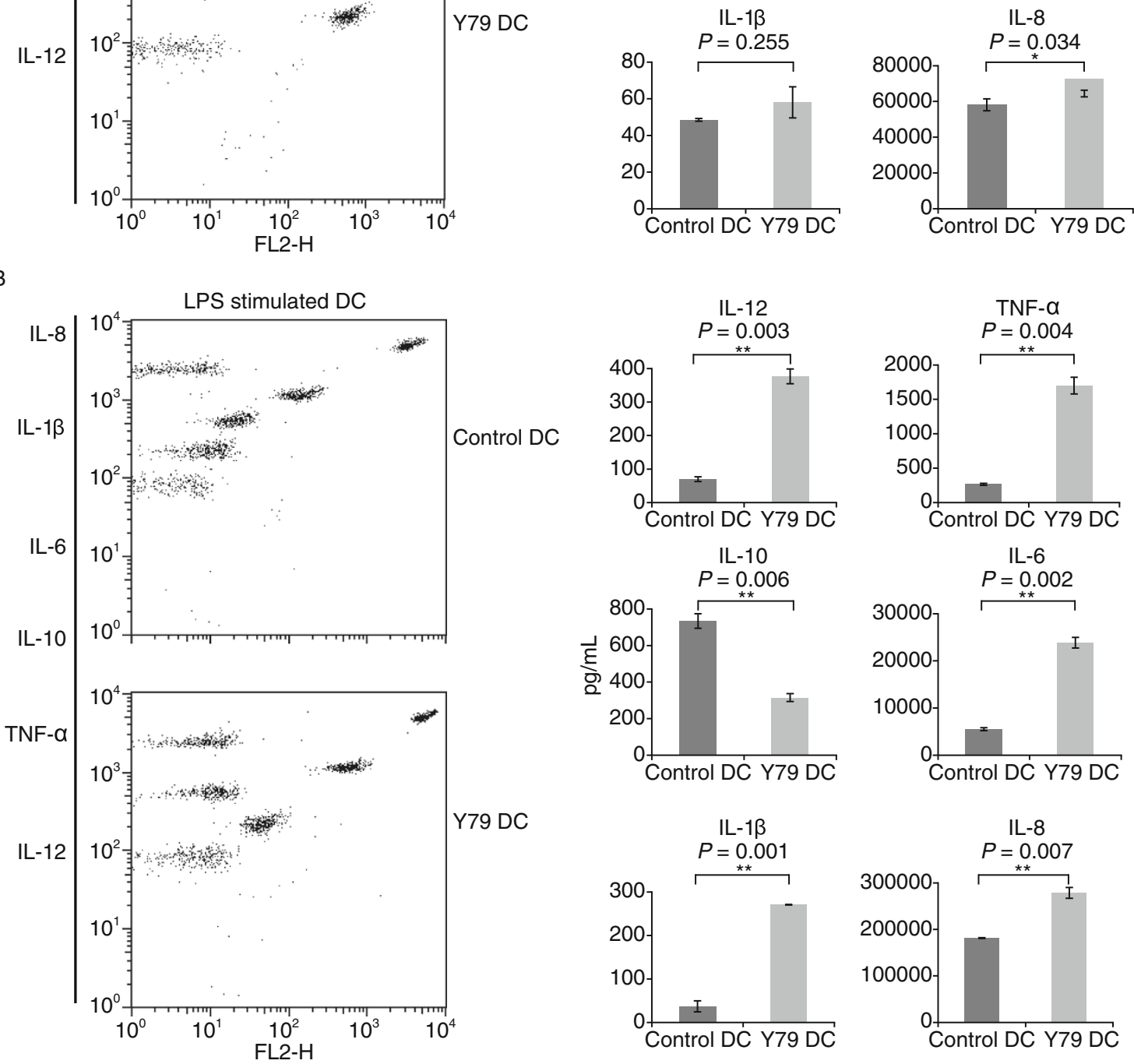

Figure 3. Production of cytokines IL-12, IL-10, TNF- $\alpha$, IL-1 $\beta$, IL-6, and IL-8 by RBcs-exposed DCs. Control DCs or RBcs-exposed DCs $\left(4 \times 10^{4}\right.$ cells/well) were treated with $20 \mathrm{ng} / \mathrm{mLTNF}-\alpha(\mathrm{A})$ or $1 \mu \mathrm{g} / \mathrm{mL} \mathrm{LPS}(B)$ for $24 \mathrm{~h}$. Concentrations of cytokines in cell-free supernatants were analyzed by CBA Human Inflammation Kit that could identify all six kinds of cytokines in a single sample. Quantitative production of a particular kind of cytokine is indicated by PE-labeled-specific Ab staining. The data are mean values \pm SD of triplicate determinations. Data shown are a representative experiment of three. ${ }^{*} P<0.05$, vs. control DCs. ${ }^{* *} P<0.01$, vs. control DCs. Y79 DC: RBcs-exposed DCs. 
present study, we first identified the alterations in the phenotype of DCs after treatment with RBcs. It was found that RBcs did not inhibit the maturation of DCs, based on the finding that RBcs had no effect on the expression of $D C$ markers CD1a and CD83. Our observation is inconsistent with some other studies in which maturation of DCs is suppressed by tumor cells or tumor condition media (Bharadwaj et al., 2007; Gabrilovich et al., 1996; Ma et al., 2010; Michielsen et al., 2011; Sombroek et al., 2002), suggesting that inhibition of DCs' maturation may be tumor-specific. Because some tumor cells can induce DC apoptosis to escape immune surveillance (Kanto et al., 2001; Kiertscher et al., 2000; Ma et al., 2010), we evaluated the effect of RBcs on DC apoptosis. As shown in the present study, RBcs failed to induce DC apoptosis. There is one report showing that mature DCs can upregulate Bcl-X to resist Fas/CD95-mediated DC apoptosis (Lundqvist et al., 2002).

Our study revealed that RBcs upregulated co-stimulatory molecules CD80 and CD86 in DCs. It has been well established that these molecules are required for optimal $\mathrm{T}$ cell activation via binding their receptors CD28 and CD152 (CTLA4) on T cells (Carreno and Collins, 2002; Collins et al., 2005). Therefore, upregulation of CD80 and CD86 by RBcs suggests that RB cells may enhance $T$ cell immune response through DCs. Consistent with this finding, an increase in T cell proliferation was observed when T cells were co-cultured with RBcs-exposed DCs in the present study. In addition, these $T$ cells were found to produce more cytokines than control RBcs-untreated DCs. These results indicate that RB cells improve DCs' capacity to activate T cell, even though phenotype and function of DCs in RB tumor microenvironment still need to be further identified.

In addition to co-stimulatory molecules CD80 and CD86, more cytokines were produced by RBcs-exposed DCs, such as IL-12, an essential cytokine stimulating Th1 responses. Consistent with IL-12 overproduction, RBcs-exposed DCs induced $\mathrm{T}$ cells to secrete more IFN-y. Interestingly, it was found that CD80/86 was synergistic with IL-12 for inducing $T$ cell proliferation and IFN-Y production (Kubin et al., 1994). Some cancer models have demonstrated the anti-tumor activities of IL-12 (Colombo and Trinchieri, 2002). Endogenous IL-12 is required for resistance to transplantable tumors or chemically induced tumors, and recombinant IL-12 treatment inhibits tumor establishment or induces tumor regression (Colombo and Trinchieri, 2002). The anti-tumor mechanisms of IL-12 may also be related to other cytotoxic lymphocytes, such as NK cells, whose maturation and activation are also dependent on IL-12 (Loza and Perussia, 2001).

Contrary to upregulation of IL-12, IL-10 was downregulated in RBcs-exposed DCs. As an immunosuppressor, IL-10 inhibits the expression of $\mathrm{MHC}$ class molecules and costimulatory molecules, and prevents the production of Th1 cytokines IL-2 and IFN-y by antigen-presenting cells (APCs). Therefore, IL-10 favors tumor evasion from immune surveillance via suppressing antigen presentation and $\mathrm{T}$ cell activation (Lippitz, 2013). IL-10 is overexpressed in a series of human cancers, which is associated with advanced stage and bad prognosis (Lippitz, 2013). Our study shows that RB cells may trigger immune responses by reducing IL-10 production, in addition to increasing IL-12 secretion by DCs.
A

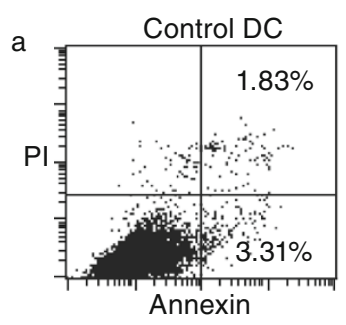

B

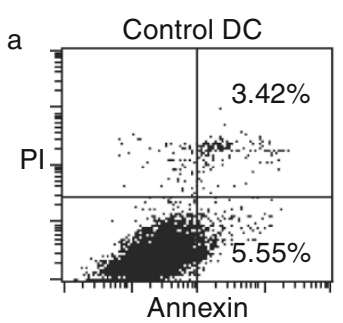

TNF- $\alpha$ stimulated DC


FITC-dUTP

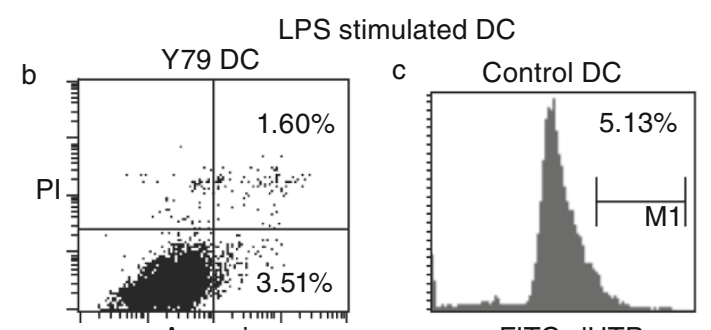

FITC-dUTP



FITC-dUTP

Figure 4. Apoptosis of RBcs-exposed DCs. Control DCs or RBcs-exposed DCs were treated with $20 \mathrm{ng} / \mathrm{mL} T N F-\alpha(A)$ or $1 \mu \mathrm{g} / \mathrm{mL}$ LPS (B) for $24 \mathrm{~h}$. DCs were stained with FITC-Annexin-V and propidium iodide (PI), and the proportion of apoptotic cells (Annexin ${ }^{+} /$ $\mathrm{PI}^{-}$) was determined by flow cytometry (a and b). Apoptosis was also assessed by a FACS-based TUNEL assay utilizing FITC-dUTP. The proportion of apoptotic cells (dUTP ${ }^{+}$) was determined by flow cytometry (c and d). Data shown are one representative experiment of three. Y79 DC: RBcs-exposed DCs. 
A

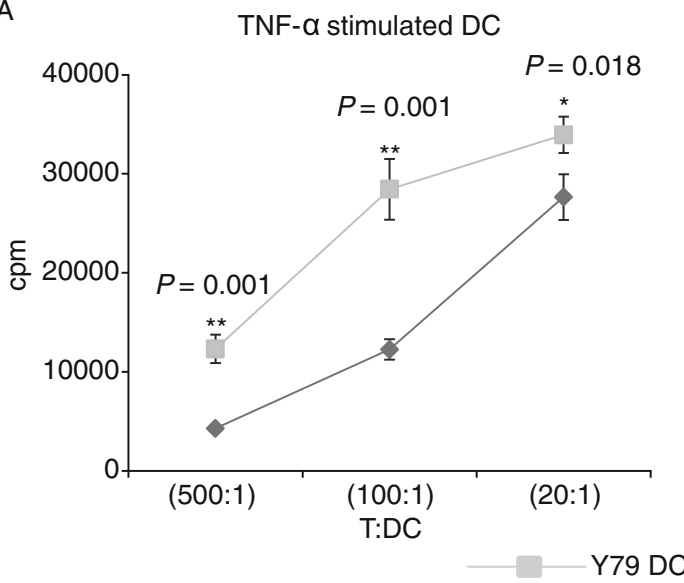

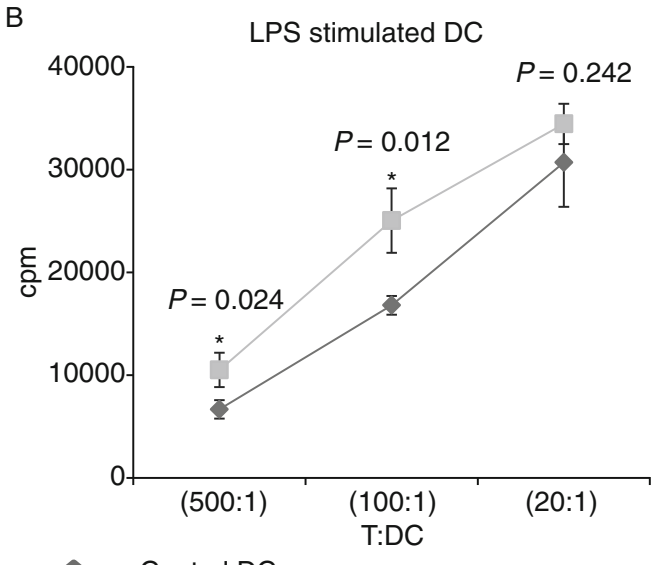

Figure 5. Enhanced allogenetic T cell proliferation stimulated by RBcs-exposed DCs. After treatment with TNF- $\alpha$ (A) or LPS (B) for $24 \mathrm{~h}$, varying numbers $(400,2000$, or 10000$)$ of irradiated (30 Gy) DCs were added to triplicate wells containing $2 \times 10^{5}$ purified allogeneic T lymphocytes and incubated for 4 days. Cultures were pulsed during the final $8 \mathrm{~h}$ of incubation, and incorporation of [ ${ }^{3} \mathrm{H}$ ]thymidine was measured. The data are mean values \pm SD of triplicate determinations. Data shown are a representative experiment of three. ${ }^{*} P<0.05$, vs control DCs. ${ }^{* *} P<0.01$, vs control DCs. Y79 DC: RBcs-exposed DCs.

In summary, we for the first time reveal that RBcs can enhance DCs' capacity to activate T cells based on the following findings: First, RBcs upregulated the expression of co-stimulatory molecules CD80 and CD86 in DCs. Second, RBcs induced the production of IL-12p70, TNF- $\alpha, I L-6, I L-1 \beta$, and IL-8, whereas reduced the secretion of IL-10 by DCs. Third, RBcs-exposed DCs stimulated $\mathrm{T}$ cell proliferation. Finally, RBcs-exposed DCs induced T cells to release Th1/ Th17 cytokines predominantly. These results suggest that RB cells may have an immunostimulatory effect on DCs, and immunotherapy aimed at DCs may be a potential way to treat RB.

\section{MATERIALS AND METHODS}

RB cell line and DCs

RB cell line Y79 was obtained from ATCC (HTB-18; Rockville, MD), and maintained in RPMl-1640 medium supplemented with $10 \mathrm{mmol} / \mathrm{L}$ HEPES, $2 \mathrm{mmol} / \mathrm{L}$ L-glutamine, $100 \mathrm{U} / \mathrm{mL}$ penicillin, $100 \mu \mathrm{g} / \mathrm{mL}$ streptomycin, and $10 \%$ heat-inactivated fetal calf serum (FCS, Sigma Chemical Co., St. Louis, MO, USA). Peripheral blood mononuclear cells (PBMCs) were isolated by Ficoll-Hypaque density gradient centrifugation from healthy individuals. To generate DCs, the mononuclear cell fraction was washed twice with RPMI-1640, suspended in RPMl-1640 at $2.5 \times 10^{6} \mathrm{cells} / \mathrm{mL}$, and seeded in a 6 -well plate (Becton) at $2 \mathrm{~mL}$ per well. The plate was incubated at $37^{\circ} \mathrm{C}$ for $2 \mathrm{~h}$, and the non-adherent cells were discarded. The adherent cells were cultured for 6 days in $2.5 \mathrm{~mL}$ RPMl supplemented with $10 \mathrm{mmol} / \mathrm{L}$ HEPES, $2 \mathrm{mmol} / \mathrm{L}$ L-glutamine, $100 \mathrm{U} / \mathrm{mL}$ penicillin, $100 \mu \mathrm{g} / \mathrm{mL}$ streptomycin, $10 \%$ heat-inactivated FCS, $50 \mathrm{ng} / \mathrm{mL}$ rhGM-CSF, and $20 \mathrm{ng} / \mathrm{mL}$ rhlL-4 (R\&D System, Minneapolis, MN). Half-volume medium exchange was performed every 3 days with medium containing fresh cytokines.

\section{Treatment of DCs with RBcs}

RBcs was prepared by seeding 10-cm dish (Falcon; BD Bioscience, Franklin Lakes, NJ, USA) with $1 \times 10^{7} \mathrm{RB}$ cell in $10 \mathrm{~mL}$ of completed medium for $24 \mathrm{~h}$ and centrifuged to remove cell debris. On day 5 of DC culture, RBcs was added to test DCs, while the same volume of culture medium was added to control DCs. On day 6, maturation of DCs was induced by adding $20 \mathrm{ng} / \mathrm{mL}$ of TNF- $\alpha$ (R\&D System) or $1 \mu \mathrm{g} / \mathrm{mL}$ of LPS (Sigma), and the phenotype of DCs was determined by flow cytometry after incubating with TNF- $\alpha$ or LPS for $24 \mathrm{~h}$. In some experiments, before adding of TNF- $\alpha$ or LPS, DCs were purified on day 6 . Briefly, RBcs-treated DCs or control DCs were washed extensively and then purified with microbeads on autoMACS columns using a Blood Dendritic Cell Isolation kit (Miltenyi Biotech, BergischGladbach, Germany) according to the manufacturer's instructions. In short, isolation of DCs was performed in a twostep procedure. First, cells labeled with the Non-DC Depletion Cocktail comprising with CD14 and CD19 magnetic beads were depleted. Then DCs were positively selected by labeled with DC Enrichment Cocktail comprising with CD1c (BDCA-1), CD304 (BDCA-4/Neuropilin-1), and CD141 (BDCA-3) magnetic beads. Purified DCs samples contained $>95 \% \mathrm{CD} \mathrm{C}^{+} \mathrm{DC}$ as evaluated by the Blood Dendritic Cell Enumeration Kit (Miltenyi Biotech).

\section{Flow cytometry and Reagents}

The following monoclonal antibodies (mAb) conjugated with either fluorescein isothiocyanate (FITC) or phycoerythrin (PE) were used: CD1a, CD83, CD40, CD80, CD86, HLA-ABC, and HLA-DR (BD 
A

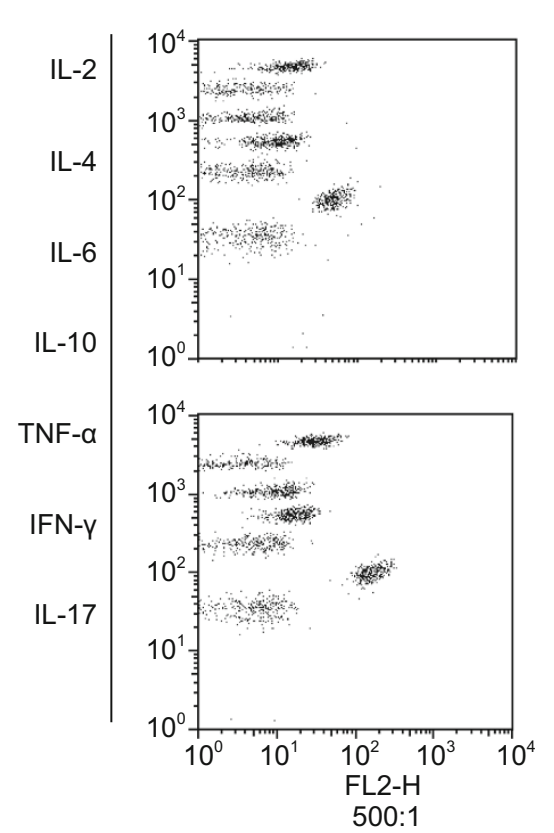

TNF- $\alpha$ stimulated DC
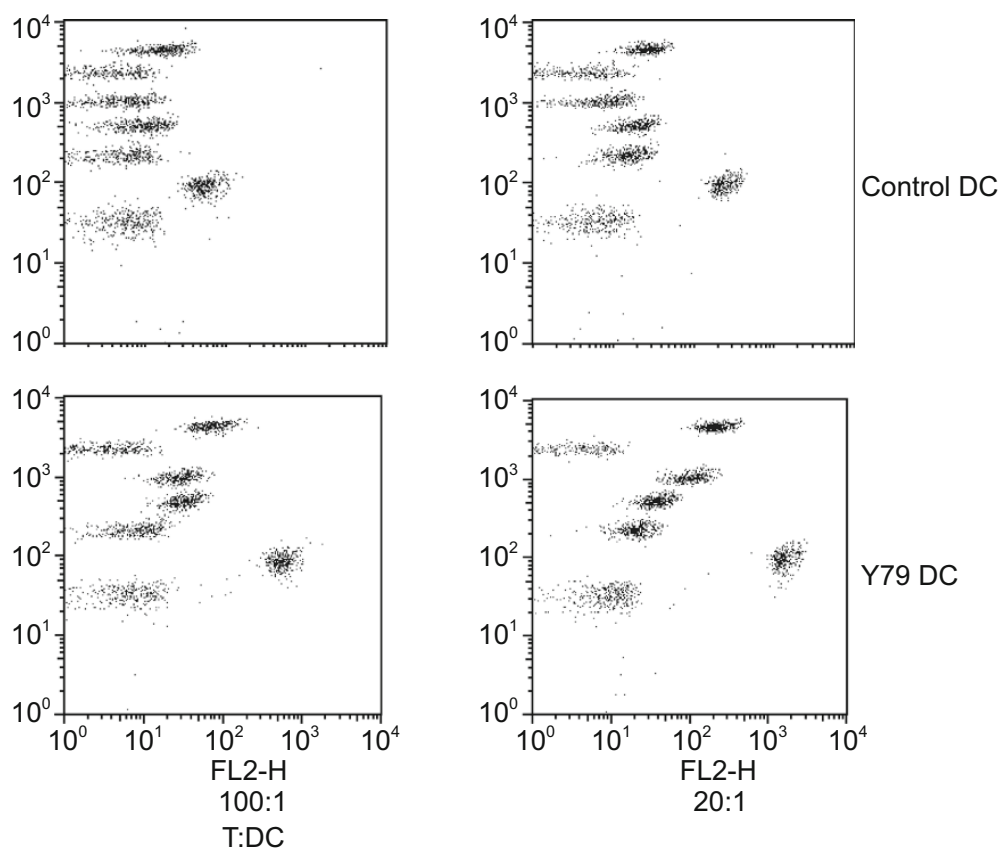

TNF- $\alpha$ stimulated DC
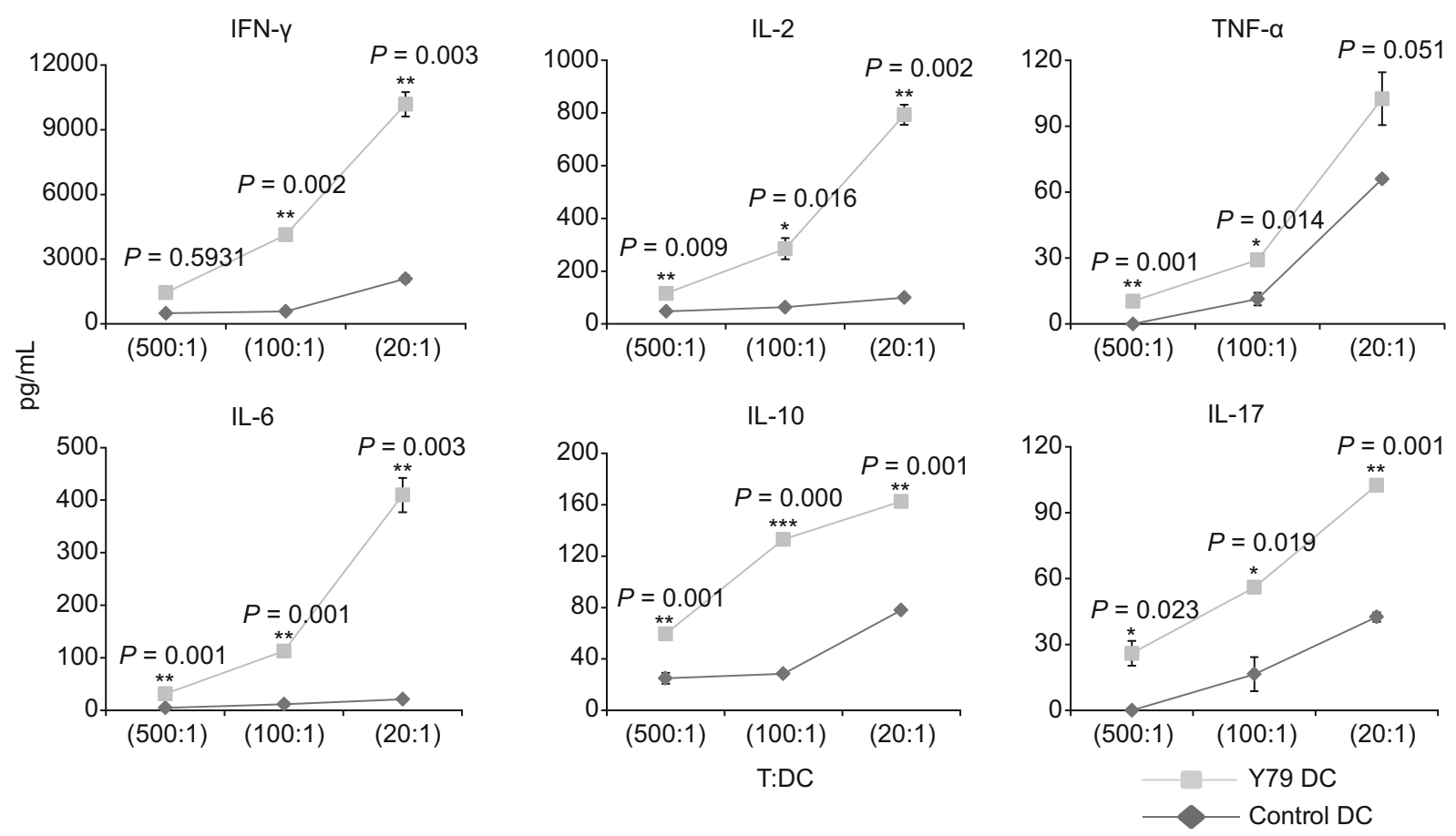

Figure 6. Increased cytokine production of by allogenetic T cell stimulated with RBcs-exposed DCs. After treatment with TNF$\alpha(A)$ or LPS (B) for $24 \mathrm{~h}$, varying numbers $(400,2000$, or 10000$)$ of irradiated (30 Gy) DCs were added to triplicate wells containing $2 \times 10^{5}$ purified allogeneic $T$ lymphocytes and incubated for 3 days. The concentrations of cytokines producted in cell-free supernatants were analyzed by CBA Human Th1/Th2/Th17 Cytokine Kit that could identify all seven kinds of cytokines in a single sample. Quantitative production of a particular kind of cytokine is indicated by PE-labeled-specific Ab staining. The data are mean values $\pm \mathrm{SD}$ of triplicate determinations. Data shown are a representative experiment of three. ${ }^{*} P<0.05$, vs. control $D C s$. ${ }^{* *} P<0.01$, vs. control DCs. ${ }^{* * *} P<0.001$, vs. control DCs. Y79 DC: RBcs-exposed DCs. 
B
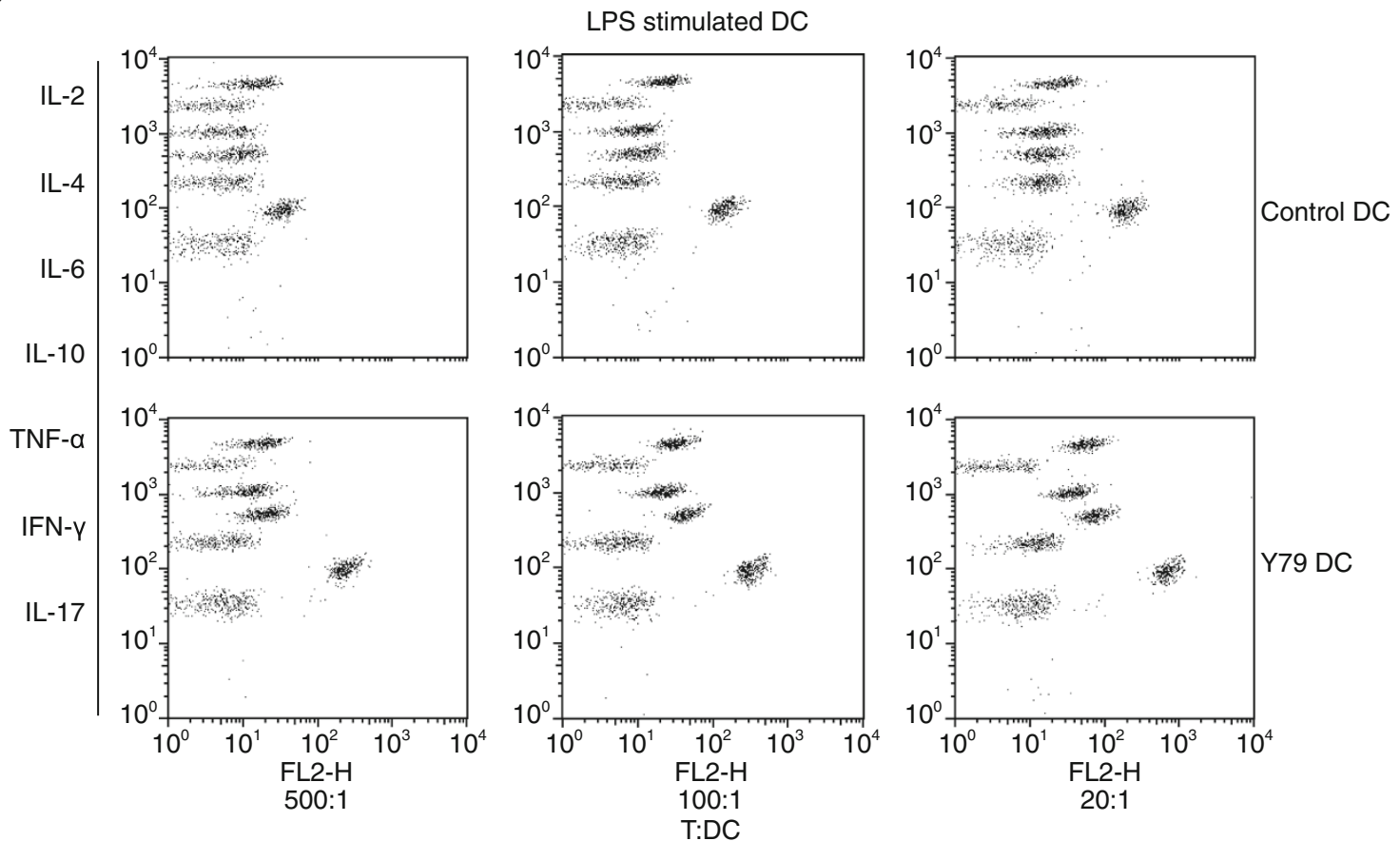

LPS stimulated DC
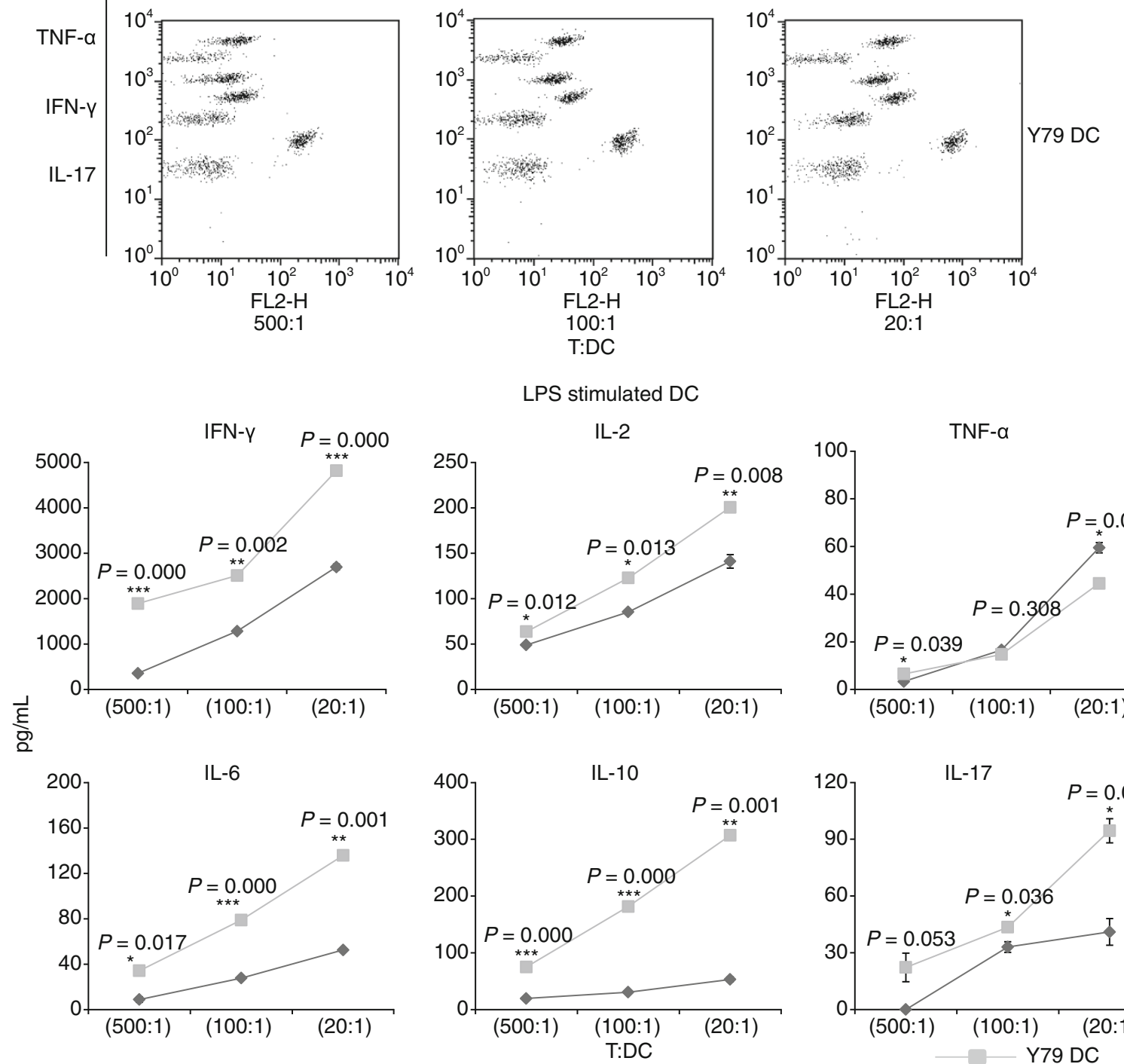
the Human Inflammation Kit (BD Bioscience) according to the protocols recommended by the manufacturer.

\section{T cell proliferation assay}

Heparinized blood samples were obtained from healthy individuals and PBMCs were isolated by Ficoll-Hypaque centrifugation. $\mathrm{CD}^{+} \mathrm{T}$ cells were purified with microbeads on auto-MACS columns using a pan $T$ cell Isolation kit (Miltenyi Biotech) according to the manufacturer's instructions. Purified $\mathrm{CD}^{+} \mathrm{T}$ cell samples contained $>98 \%$ $\mathrm{CD}^{+} \mathrm{T}$ cells as determined by flow cytometry. DCs were irradiated with an X-irradiator (Gammacell 40 Exactor; MDS Nordion International, Inc., Ottawa, Ontario, CA) at 30G. Purified allogeneic $\mathrm{CD}^{+} \mathrm{T}$ cell seeded into a round-bottom 96-well micro-culture plate at $2.0 \times 10^{5}$ per well were co-cultured with purified, stimulated, irradiated DCs at T:DC ratio of 20:1, 100:1, or 500:1. All experiments were done in triplicate, and $\mathrm{T}$ cells alone were used as the background control. The cultures were incubated for 4 days at $37^{\circ} \mathrm{C}$ in $5 \% \mathrm{CO}_{2}$ in air, pulsed with $\left[{ }^{3} \mathrm{H}\right]$-thymidine $(1.0 \mu \mathrm{Ci} / 10 \mu \mathrm{L} /$ well $)$ during the last $8 \mathrm{~h}$ of incubation, and then harvested onto glass filters with an automated cell harvester. Radioactivity was assessed by liquid scintillation spectrometry (Tomtec, Orange, CT), and expressed as counts per minute.

\section{T cell-derived cytokine assays}

Cell free supernatant was collected from T cell-DC co-culture system $72 \mathrm{~h}$ later and levels of IFN- $\gamma$, TNF- $\alpha$, IL-10, IL-6, IL-4, IL-2, and IL-17 were measured by CBA assay with the Human Th1/Th2/Th17 Kit (BD Bioscience) according to the protocols recommended by the manufacturer.

\section{Statistical analyses and reproducibility}

Experiments were repeated at least twice and usually three times. Results were expressed as mean \pm SD. Statistical analyses were performed by independent $t$-test using the computer software PEMS 3.1 for Windows software (Package for Encyclopaedia of Medical Statistics, Chengdu, China) or PASW Statistics 18. $P<0.05$ was considered significant. Significance was denoted by an asterisk in the figures.

\section{ACKNOWLEDGEMENTS}

This work is funded by the grants from the Ministry of Science and Technology of China (S \& T major Program: No. 2012ZX1004701001-002), the National Basic Research Program (973 Program) (No. 2013CB531502), the National Nature Science Foundation of China (Grant Nos. 31170829, 31070783, and 81021003), and Beijing Natural Science Foundation (5112022).

\section{ABBREVIATIONS}

APCs, antigen-presenting cells; DCs, Dendritic cells; mAb, monoclonal antibodies; M-CSF, macrophage colony-stimulating factor; $\mathrm{MHC}$, major histocompatibility complex; NF-KB, nuclear factor kappa-B; PBMCs, peripheral blood mononuclear cells; RB, retinoblastoma; RBcs, RB cell supernatant; STAT3, signal transducers and activators of transcription 3; TGF- $\beta$, transforming growth factor- $\beta$; VEGF, vascular endothelial growth factor.

\section{COMPLIANCE WITH ETHICS GUIDELINES}

Juan Ma, Huamin Han, Li Ma, Changzhen Liu, Xin Xue, Pan Ma, Xiaomei $\mathrm{Li}$, and Hua Tao declare that they have no conflict of interest.

All procedures followed were in accordance with the ethical standards of the responsible committee on human experimentation (institutional and national) and with the Helsinki Declaration of 1975, as revised in $2000(5)$.

\section{OPEN ACCESS}

This article is distributed under the terms of the Creative Commons Attribution License which permits any use, distribution, and reproduction in any medium, provided the original author(s) and the source are credited.

\section{REFERENCES}

Ataera H, Hyde E, Price KM, Stoitzner P, Ronchese F (2011) Murine melanoma-infiltrating dendritic cells are defective in antigen presenting function regardless of the presence of CD4CD25 regulatory T cells. PLoS One 6:e17515

Beckebaum S, Zhang X, Chen X, Yu Z, Frilling A, Dworacki G, Grosse-Wilde H, Broelsch CE, Gerken G, Cicinnati VR (2004) Increased levels of interleukin-10 in serum from patients with hepatocellular carcinoma correlate with profound numerical deficiencies and immature phenotype of circulating dendritic cell subsets. Clin Cancer Res 10:7260-7269

Bharadwaj U, Li M, Zhang R, Chen C, Yao Q (2007) Elevated interleukin-6 and G-CSF in human pancreatic cancer cell conditioned medium suppress dendritic cell differentiation and activation. Cancer Res 67:5479-5488

Carreno BM, Collins M (2002) The B7 family of ligands and its receptors: new pathways for costimulation and inhibition of immune responses. Annu Rev Immunol 20:29-53

Chaux P, Favre N, Martin M, Martin F (1997) Tumor-infiltrating dendritic cells are defective in their antigen-presenting function and inducible B7 expression in rats. Int J Cancer 72:619-624

Collins M, Ling V, Carreno BM (2005) The B7 family of immuneregulatory ligands. Genome Biol 6:223

Colombo MP, Trinchieri G (2002) Interleukin-12 in anti-tumor immunity and immunotherapy. Cytokine Growth Factor Rev 13:155-168

Dieu-Nosjean MC, Antoine M, Danel C, Heudes D, Wislez M, Poulot V, Rabbe N, Laurans L, Tartour E, de Chaisemartin L et al (2008) Long-term survival for patients with non-small-cell lung cancer with intratumoral lymphoid structures. J Clin Oncol 26:4410-4417

Gabrilovich DI, Chen HL, Girgis KR, Cunningham HT, Meny GM, Nadaf S, Kavanaugh D, Carbone DP (1996) Production of vascular endothelial growth factor by human tumors inhibits the functional maturation of dendritic cells. Nat Med 2:1096-1103

Gottfried E, Kreutz M, Mackensen A (2008) Tumor-induced modulation of dendritic cell function. Cytokine Growth Factor Rev 19:65-77 
Houston SK, Murray TG, Wolfe SQ, Fernandes CE (2011) Current update on retinoblastoma. Int Ophthalmol Clin 51:77-91

Iwamoto M, Shinohara H, Miyamoto A, Okuzawa M, Mabuchi $\mathrm{H}$, Nohara T, Gon G, Toyoda M, Tanigawa N (2003) Prognostic value of tumor-infiltrating dendritic cells expressing CD83 in human breast carcinomas. Int J Cancer 104:92-97

Kanto T, Kalinski P, Hunter OC, Lotze MT, Amoscato AA (2001) Ceramide mediates tumor-induced dendritic cell apoptosis. J Immunol 167:3773-3784

Khetan V, Mathur G, Kumar SK, Gopal L (2013) Late recurrence of tumor necessitating enucleation in an adult onset retinoblastoma. Ophthalmic Genet 34:87-89

Kiertscher SM, Luo J, Dubinett SM, Roth MD (2000) Tumors promote altered maturation and early apoptosis of monocytederived dendritic cells. J Immunol 164:1269-1276

Kubin M, Kamoun M, Trinchieri G (1994) Interleukin 12 synergizes with B7/CD28 interaction in inducing efficient proliferation and cytokine production of human T cells. J Exp Med 180:211-222

Ladanyi A, Kiss J, Somlai B, Gilde K, Fejos Z, Mohos A, Gaudi I, Timar J (2007) Density of DC-LAMP(+) mature dendritic cells in combination with activated $\mathrm{T}$ lymphocytes infiltrating primary cutaneous melanoma is a strong independent prognostic factor. Cancer Immunol Immunother 56:1459-1469

Lim DS, Kim JH, Lee DS, Yoon CH, Bae YS (2007) DC immunotherapy is highly effective for the inhibition of tumor metastasis or recurrence, although it is not efficient for the eradication of established solid tumors. Cancer Immunol Immunother 56:18171829

Lippitz BE (2013) Cytokine patterns in patients with cancer: a systematic review. Lancet Oncol 14:e218-e228

Loza MJ, Perussia B (2001) Final steps of natural killer cell maturation: a model for type 1 type 2 differentiation? Nat Immunol 2:917-924

Lundqvist A, Nagata T, Kiessling R, Pisa P (2002) Mature dendritic cells are protected from Fas/CD95-mediated apoptosis by upregulation of $\mathrm{Bcl}-\mathrm{X}(\mathrm{L})$. Cancer Immunol Immunother 51:139144

Ma J, Usui Y, Takeuchi M, Okunuki Y, Kezuka T, Zhang L, Mizota A, Goto H (2010) Human uveal melanoma cells inhibit the immunostimulatory function of dendritic cells. Exp Eye Res 91:491499

Merchant TE, Gould CJ, Wilson MW, Hilton NE, Rodriguez-Galindo C, Haik BG (2004) Episcleral plaque brachytherapy for retinoblastoma. Pediatr Blood Cancer 43:134-139

Michielsen AJ, Hogan AE, Marry J, Tosetto M, Cox F, Hyland JM, Sheahan KD, O'Donoghue DP, Mulcahy HE, Ryan EJ et al (2011)
Tumour tissue microenvironment can inhibit dendritic cell maturation in colorectal cancer. PLoS One 6:e27944

Movassagh M, Spatz A, Davoust J, Lebecque S, Romero P, Pittet M, Rimoldi D, Lienard D, Gugerli O, Ferradini L et al (2004) Selective accumulation of mature DC-Lamp+ dendritic cells in tumor sites is associated with efficient T-cell-mediated antitumor response and control of metastatic dissemination in melanoma. Cancer Res 64:2192-2198

Nakakubo Y, Miyamoto M, Cho Y, Hida Y, Oshikiri T, Suzuoki M, Hiraoka K, Itoh T, Kondo S, Katoh H (2003) Clinical significance of immune cell infiltration within gallbladder cancer. $\mathrm{Br} \mathrm{J}$ Cancer 89:1736-1742

Preynat-Seauve O, Schuler P, Contassot E, Beermann F, Huard B, French LE (2006) Tumor-infiltrating dendritic cells are potent antigen-presenting cells able to activate $T$ cells and mediate tumor rejection. J Immunol 176:61-67

Preynat-Seauve O, Contassot E, Schuler P, French LE, Huard B (2007) Melanoma-infiltrating dendritic cells induce protective antitumor responses mediated by T cells. Melanoma Res 17:169-176

Sandel MH, Dadabayev AR, Menon AG, Morreau H, Melief CJ, Offringa R, van der Burg SH, Janssen-van Rhijn CM, Ensink NG, Tollenaar RA et al (2005) Prognostic value of tumor-infiltrating dendritic cells in colorectal cancer: role of maturation status and intratumoral localization. Clin Cancer Res 11:2576-2582

Schueler AO, Jurklies C, Heimann H, Wieland R, Havers W, Bornfeld N (2003) Thermochemotherapy in hereditary retinoblastoma. $\mathrm{Br} \mathrm{J}$ Ophthalmol 87:90-95

Sombroek CC, Stam AG, Masterson AJ, Lougheed SM, Schakel MJ, Meijer CJ, Pinedo HM, van den Eertwegh AJ, Scheper RJ, de Gruijl TD (2002) Prostanoids play a major role in the primary tumor-induced inhibition of dendritic cell differentiation. J Immunol 168:4333-4343

Stoitzner P, Green LK, Jung JY, Price KM, Atarea H, Kivell B, Ronchese $F$ (2008) Inefficient presentation of tumor-derived antigen by tumor-infiltrating dendritic cells. Cancer Immunol Immunother 57:1665-1673

Treilleux I, Blay JY, Bendriss-Vermare N, Ray-Coquard I, Bachelot T, Guastalla JP, Bremond A, Goddard S, Pin JJ, Barthelemy-Dubois $C$ et al (2004) Dendritic cell infiltration and prognosis of early stage breast cancer. Clin Cancer Res 10:7466-7474

Wang T, Niu G, Kortylewski M, Burdelya L, Shain K, Zhang S, Bhattacharya R, Gabrilovich D, Heller R, Coppola D et al (2004) Regulation of the innate and adaptive immune responses by Stat3 signaling in tumor cells. Nat Med 10:48-54

Zou W (2005) Immunosuppressive networks in the tumour environment and their therapeutic relevance. Nat Rev Cancer 5:263-274 